\title{
Primary Care Is an Essential Ingredient to a Successful Population Health Improvement Strategy
}

\author{
Jennifer E. DeVoe, MD, DPhil
}

Primary care teams bridge health care to other sectors, making effective connections between health care and health. For health care systems to improve patient and population health, the important role of primary care must be recognized, celebrated, and strengthened. This commentary explores several of the current hot topics in policy discussions (eg, social determinants of health, population health) and gives examples of how these theoretical discussions are relevant to the real world of patient care. It concludes with a few key points on how the system can better support the important population health improvement work done by primary care teams. Changes in the way primary care is delivered, reimbursed, and measured are needed to support the health promoting and healing work that happens continuously, not just during a clinic visit or inside the clinic walls. Renewed investments must be made to strengthen delivery models that enable longitudinal, trusting relationships to develop between patients and primary care teams. Payment systems must shift away from fee-for-service models to new holistic reimbursement methods that reflect the value of a comprehensive scope of primary care practice and continuity of care. Measuring what matters in primary care will help to realign our focus on health. (J Am Board Fam Med 2020;33:468-472.)

Keywords: Continuity of Patient Care, Delivery of Health Care, Population Health, Primary Health Care, Social Determinants of Health

Health encompasses much more than health care, and receiving more overall health care does not equate with having better health. ${ }^{1-3}$ Yet, a greater supply of primary care physicians (PCPs) in a community is associated with lower mortality and better population health. ${ }^{4}$ What is it about primary care that matters? Given that health care accounts for only $10 \%$ of the variation in premature mortality, ${ }^{5}$ it is likely that primary care's lifesaving impact stems largely from high-functioning primary care teams identifying and addressing many of the other factors impacting health. Often referred to as social determinants of health (SDH), these factors are the interconnected social, economic, environmental, and behavioral influences on health-the

\footnotetext{
This article was externally peer reviewed.

Submitted 21 August 2019; revised 09 January 2020; accepted 13 January 2020.

From the Department of Family Medicine, Oregon Health \& Science University, Portland.

Funding: None.

Conflict of interest: No conflicts of interest or competing interests to disclose.

Corresponding author: Jennifer E. DeVoe, MD, DPhil, the Department of Family Medicine, Oregon Health \& Science University, Portland, OR 97239 (E-mail: devoej@ohsu.edu).
}

root causes of wellness or illness. Thus, primary care's critical role in improving population health outcomes stems from being a powerful and critical connector between a population's health care and health. ${ }^{1-6}$

\section{Social Determinants of Health}

In 2010, the World Health Organization created a framework to outline the SDH, which includes 9 interdependent factors impacting health: education, employment, health systems and services, housing, income and wealth, physical environment, transportation, public safety, and social environment. ${ }^{7}$ By highlighting the diverse and interconnected factors across several domains that impact health, this SDH framework helps to foster an understanding that a complex sociocultural environment shapes health and suggests that interventions to address adverse SDH can improve a person's health as well as the health of a population. Theoretically, PCPs and primary care teams are well poised to identify a patient's adverse SDH and intervene to bridge health care and social services to improve patient and population health. ${ }^{3}$ But, how exactly does this 
happen in the real world? During the past 20 years, patients and families have taught me important empirical lessons to demonstrate how this theory applies to real-world settings.

\section{Spencer}

I met Spencer during residency while working nights in the emergency department (ED). After seeing him a couple of weeks in a row for preventable complications from his diabetes and congestive heart failure, he asked me when I was scheduled to work my next ED shift because he found it helpful to have continuity with the same emergency physician. I told him that my ED rotation was ending and I would be transitioning to my obstetrics rotation. I recommended that he schedule visits with his PCP more regularly. With a quizzical look on his face, he told me he had never had a PCP and was unsure how to find one. I offered to be his PCP (not realizing he needed to ride 3 different buses to visit my clinic).

Over the next several years, our primary care team had the privilege of helping Spencer manage his complex chronic diseases, coordinate his specialty referrals, and improve his mental health. Once his trust in us deepened, he started bringing his wife and other family members to our clinic, too. He eventually shared his fears about their unsafe housing situation and their need for healthier food and reliable transportation. Our team helped him find safer housing and connected him with mental health care and other social services that his family needed. Several years later, he remarked to our team that he never needed to go back to the ED after meeting me there and that my small gesture offering to be his PCP changed his life. Our team's work enabled him to receive care that was patientand family-centered, comprehensive in addressing his social care needs, and coordinated across the medical neighborhood. ${ }^{8,9}$ Eliminating his need to return to the ED also saved the system a significant amount of money.

The lifesaving work that happens in primary care is often less visible than the work done by trauma surgeons and oncologists who bring people back from the brink of death. Primary care lifesavers have the power to heal, which happens over yearsthrough building trusting relationships during a lifetime, creating patient-centered medical homes, connecting patients to social services, and advocating for healthy policies in communities. ${ }^{3,10,11}$ The stories of Spencer and José (below) are representative of the countless stories held dear by every primary care team about patients and families we have been privileged to serve. When each of us is reminded about our individual stories and experiences, it is easy to understand the way in which PCPs and teams impact health beyond the health care services we provide and how, taken to scale for a population, having PCPs in a community can make a difference to a community's health. ${ }^{4,12}$

\section{José}

José was one of the first babies I had the privilege of delivering (more accurately: his mom delivered him, I was honored to attend the delivery). As a single parent living in poverty, his mom continuously struggles to make ends meet, and they have been forced to move multiple times to find safe, affordable housing. Amid the turmoil in their lives, I feel fortunate to have been their family's PCP for more than 15 years. Recently, I offered José the option to change to a new PCP. Now in his teens, I thought he might be more comfortable with a male PCP. He emphatically told me "no" because I had cared for him since birth, and he trusts and respects me as his doctor. He told me that he has only a few adults in his life whom he trusts.

Before entering the examination room at his most recent well child visit, our medical assistant remarked that he had lost weight and looked sad. He usually does not like to complete the standard forms we give patients at check-in with questions about their health behaviors, depression symptoms, and other concerns. I glanced at his forms while opening the door to say "hello"; not surprisingly, they were blank that day. I started a casual conversation about how he was liking school and if he was still enjoying video games. I wove in questions about his mental health, substance use, school performance, sexual activity, and also asked about food insecurity. He dodged most of my questions about alcohol, drugs, and sex. However, he did confide in me that he and his mom often do not have enough food to last through the month, that he is flunking several classes, that his mom lost her driver's license because they could not afford car insurance, and that he is having trouble controlling his anger. I was able to connect him with our social worker to get additional assistance. She also arranged for him to start seeing a psychologist regularly, adding 
another trusted adult into his life. Knowing that they had limited transportation options to get to the clinic, our team started checking in with José and his mom regularly via telephone and patient portal messages. Several months later, his mother shared with me that she believed our team's interventions saved his life at a time when he was seriously contemplating suicide.

An automated review of Jose's medical chart during this period of time would have shown that he was in perfect health. He attended his yearly wellchild visits, and he was up-to-date on his immunizations. He had a normal vision and hearing screening test; he was getting regular dental care. He had a normal blood pressure and body mass index. His medical list contained only multivitamins, and he had no chronic medical conditions. Contrary to what the system would have seen with an automated review, our long-term relationship with José and his mom helped to uncover that he was at significant risk. Our primary care team's comprehensive approach and the continuity of care we provided enabled us to learn that he had social and behavioral needs that were negatively influencing his health. By building trust and addressing adverse $\mathrm{SDH}$, we may have prevented a suicide attempt.

\section{Primary Care's Role in Addressing Adverse Social Determinants of Health}

Spencer, José, and many others through the years have taught me about the important role primary care teams play in identifying and addressing adverse SDH for patients. ${ }^{3,13}$ Sometimes, this role entails administering a survey to ask patients about social factors impacting their ability to be healthy, ${ }^{13-15}$ but often it goes far beyond this type of screening activity. The number of screenings completed in a practice is easy to measure. More difficult to capture or describe is how the dedication and compassion of primary care teams enables many patients to share painful stories about trauma and adversities they are experiencing. Primary care teams create safe spaces for patients and their family members to share some of their most intimate thoughts and fears. ${ }^{10}$

\section{Bolstering Support for Primary Care That Improves Population Health}

Given primary care's lifesaving impact on populations and the critical ways in which primary care bridges health care and health, it is not surprising that many population health improvement strategies include strengthening primary care. Bolstering primary care does not simply mean hiring more primary care providers and adding more patients to their panels. It means supporting primary care teams to strengthen relationships, to ensure continuity, and to better integrate and coordinate care. Focused efforts on improving delivery, payment, and measurement systems for primary care are great places to start.

\section{Delivery Models}

Before I could effectively help Spencer or José in addressing their social care and mental health needs, we had to build trust. Delivery models that preserve continuity between patients and PCPs as well as build and sustain primary care teams tightly connected with each other will enable effective, integrated care. As health care systems develop new models that cater to market demands for immediate access and convenient online scheduling, they must also pay close attention to the importance of maintaining and improving delivery models built on primary care's core tenets of established relationships and continuity of care. ${ }^{16}$ In other words, new technologies (eg, virtual visits) and expanded access points (eg, urgent care centers) are not sufficient replacements for long-term patient-physician relationships but could enhance primary care's positive impact if implemented to facilitate, rather than fragment, continuity. One example of how this could be done is through enabling more frequent communication between patients and primary care teams, especially at critical junctures in life, as was the case with José during his teen years.

\section{Payment Models}

A fee-for-service payment model that reimburses short, episodic, face-to-face patient visits with a PCP to address an acute complaint has been the dominant payment paradigm for several decades. This narrowly focused financing model is not adequate to enable primary care teams to do much of the important work needed to build longitudinal relationships, to manage chronic diseases, to integrate behavioral health services, and to address patients' adverse SDH. New payment models should reflect the value of taking care of all primary health care needs for a population of patients; these models should adequately support all modes of care delivery and 
patient-clinician-team communication to enhance connections and enable healing. In addition to serving patients better, this model of comprehensive care saves the system money downstream. ${ }^{17,18}$

In short, payment should align with the services needed to improve continuity, comprehensiveness, integration, and coordination. Some of the most important interventions for improving José's health have been exchanging short and frequent e-mail messages-letting him know someone cares about him. Yet, we do not have mechanisms to bill his insurance plan for our team's important work in this area. For Spencer, efforts by our social workers, nurses, and medical assistants to connect his family with social services were critical. Most of these services were also not billable, even though the health care cost savings that resulted from him not returning to the ED were tremendous.

\section{Measurement}

Many health care institutions now have sophisticated data systems and analytic capabilities; our population health analytics tools have dashboards with metrics for measuring an enormous number of indicators. How do we ensure that we are measuring what matters most to patients, families, and communities? ${ }^{19}$ I can click a button to see my performance on diabetes care quality processes and hypertension management. Unfortunately, our system's population health dashboards do not measure Spencer's ED visits that our primary care team has prevented, the stable housing we helped him obtain, and the significant reductions in his self-destructive behaviors that resulted from getting regular mental health care. Similarly, our team's work in addressing José's food insecurity, treating his depression, and preventing a suicide attempt are invisible in the data reports we receive every month.

\section{Summary}

PCPs and primary care teams facilitate effective connections between health care and health. Investing in delivery models that preserve and enhance longitudinal, trusting relationships between patients and primary care teams is foundational to the success of any population health improvement program. Payment systems must break out of fee-for-service models to align compensation with a comprehensive approach and continuity of care to better support the important work that happens continuously, not just during a clinic visit or inside the clinic walls. ${ }^{16-18}$ Shifting away from assessing easy-tomeasure indicators and working on developing measures that matter to primary care will help primary care teams to more effectively focus on health. ${ }^{19}$ In brief, primary care is an essential ingredient to any population health improvement strategy and will have maximum impact on improving a population's health if health care systems and payers stop flocking toward episodic, convenience models of care. Instead, they need to pay for longitudinal, comprehensive primary care provided by multidisciplinary teams and shift toward measuring more of what matters to patient, community, and population health.

Thank you to Amanda Delzer-Hill for reviewing manuscript drafts and giving critical feedback. I am grateful to the many mentors and patients who have enriched my life and taught me so much about the importance of primary care.

To see this article online, please go to: http://jabfm.org/content/ 33/3/468.full.

\section{References}

1. Committee on Applying Neurobiological and Sociobehavioral Sciences from Prenatal through Early Childhood Development: A Health Equity Approach. National Academies of Sciences, Engineering, and Medicine. Vibrant and healthy kids: aligning science, practice, and policy to advance health equity. DeVoe JE, Geller A, Negussie Y, eds. Washington DC: National Academies Press; 2019.

2. Lantz PM. The medicalization of population health: who will stay upstream? Milbank Quarterly 2019;97:36-9.

3. Woolf S. Necessary but not sufficient: why health care alone cannot improve population health and reduce health inequities. Ann Fam Med 2019;17: 196-9.

4. Basu S, Berkowitz SA, Phillips RL, Bitton A, Landon BE, Phillips RS. Association of primary care physician supply with population mortality in the United States 2005-2015. JAMA Intern Med 2019;179:506-14.

5. Kaplan RM, Milstein A. Contributions of health care to longevity: a review of 4 estimation methods. Ann Fam Med 2019;17:267-72.

6. Hollander-Rodriguez J, DeVoe JE. Family medicine's task in population health: defining it and owning it. Fam Med 2018;50:659-61.

7. World Health Organization. [Internet]. Geneva, Switzerland: Author; 2010 [cited 2019 Dec 9]. A conceptual framework for action on the social determinants of health. Social Determinants of 
Health Discussion Paper 2. Available from: https:// apps.who.int/iris/bitstream/handle/10665/44489/ 9789241500852_eng.pdf;jsessionid=2553D4509D797840249A6CDE188B04E1? sequence=1.

8. Gottlieb LM. Learning from Alma Ata: the medical home and comprehensive primary health care. J Am Board Fam Med 2009;22:242-6.

9. Kieber-Emmons AM, Miller WL. The patient-centered medical home (PCMH) framing typology for understanding the structure, function, and outcomes of PCMHs. J Am Board Fam Med 2017; 30:472-9.

10. Scott JG, Cohen D, Dicicco-Bloom B, Miller WL, Stange KC, Crabtree BF. Understanding healing relationships in primary care. Ann Fam Med 2008;6:315-22.

11. Mainous AII, Goodwin MA, Stange KC. Patientphysician shared experiences and value patients place on continuity of care. Ann Fam Med 2004;2: 452-4.

12. Pereira Gray DJ, Sidaway-Lee K, White E, Thorne A, Evans PH. Continuity of care with doctors-a matter of life and death? A systematic review of continuity of care and mortality. BMJ Open 2018;8: e021161.

13. DeVoe JE, Bazemore AW, Cottrell EK, et al. Perspective in primary care: a conceptual frame- work and path for integrating social determinants into primary care practice. Ann Fam Med 2016; 14:104-8.

14. Pinto AD, Glattstein-Young G, Mohamed A, Bloch G, Leung F-H, Glazier RH. Building a foundation to reduce health inequities: routine collection of sociodemographic data in primary care. J Am Board Fam Med 2016;29:348-55.

15. Gold R, Cottrell E, Bunce A, et al. Developing electronic health record (EHR) strategies related to health center patients' social determinants of health. J Am Board Fam Med 2017;30:428-47.

16. Bazemore A, Petterson S, Peterson LE, Bruno R, Chung Y, Phillips RL. Higher primary care physician continuity is associated with lower costs and hospitalizations. Ann Fam Med 2018;16:492-7.

17. Bazemore A, Petterson S, Peterson LE, Phillips RL. More comprehensive care among family physicians is associated with lower costs and fewer hospitalizations. Ann Fam Med 2015;13:206-13.

18. McConnell KJ. Investing in primary care and dismantling fee-for-service. Milbank Quarterly 2019; 97:636-40.

19. Etz RS, Zyzanski SJ, Gonzalez MM, Reves SR, O’Neal JP, Stange KC. A new comprehensive measure of high-value aspects of primary care. Ann Fam Med 2019;17:221-30. 